Journal of Engineering Sciences, Assiut University, Vol. 37, No. 3 pp. 621-637, May 2009

\title{
A SIMPLE NETWORK MODEL OF THE TRANSIENT BEHAVIOR OF FLAT PLATE HEAT PIPES
}

\author{
M. H. Ahmed, N. Y. Abdel-Shafi and Ali K. Abdel-Rahman \\ Department of Mechanical Engineering, Faculty of Engineering, \\ Assiut University, Assiut 71516, EGYPT
}

(Received April 28, 2009 Accepted June 4, 2009)

\begin{abstract}
A simple network analysis to study the transient thermal performance of a flat plate heat pipe is developed in this study. The transient behavior of the flat plate heat pipe is described by simple, first order, linear ordinary differential equations that can be solved easily using matrix inverse method. A comparison of the results obtained using this simplified model with some existing experimental results available in the literature is conducted. It is found that the network model can be successfully used to simulate the transient behavior of flat plate heat pipes. Parametric study is conducted to investigate the effect of different parameters on the maximum and minimum temperatures of the flat plate heat pipe.
\end{abstract}

KEYWORDS: Flat plate heat pipe; Network modeling; Transient thermal performance.

\section{INTRODUCTION}

Heat pipes have widely used in heat transfer related application such as solar collectors, energy storage and electronic cooling. A comprehensive review of the physical phenomena and applications of heat pipes is given by Faghri [1], Peterson [2] and Chi [3]. A flat plate heat pipe offers many advantages over the conventional cylindrical design, such as increased surface area to volume ratio and the ability to stack or layer the energy conversion system on both sides of the flat heat pipe to utilize available energy. The flat plate heat pipe finds applications for much localized heat dissipation where it is difficult to effectively utilize a conventional cylindrical heat pipe due to limited heat source and sink areas (Xiao and Faghri [4] and Doa et al. [5]). It also finds applications in spacecraft radiator segments and many commercial devices (Lefevre et al. [6] and Sonan et al. [7]). However, just few researchers investigated the flat plate heat pipe analytically, and experimentally.

Zhu and Vafai [8] studied analytically steady incompressible vapor and liquid flow in a horizontal asymmetrical flat plate heat pipe. Three-dimensional analysis was conducted for one internal channel. The analysis was based on using simpler boundary layer equations.

Vafai and Wang [9] proposed an asymmetrical flat plate heat pipe design. Heat input was applied at the top center surface of the heat pipe, so that the flow and heat transfer becomes asymmetrical. The vapor space was divided into several channels by vertical wicks to transport liquid from the bottom wick to the top one. The vapor flow was modeled by using parabolic velocity profiles for the upper and lower parts. The liquid flow was modeled using Darcy's law with the assumption of equal flow rates in the top and bottom wicks. 


\section{NOMENCLATURE}

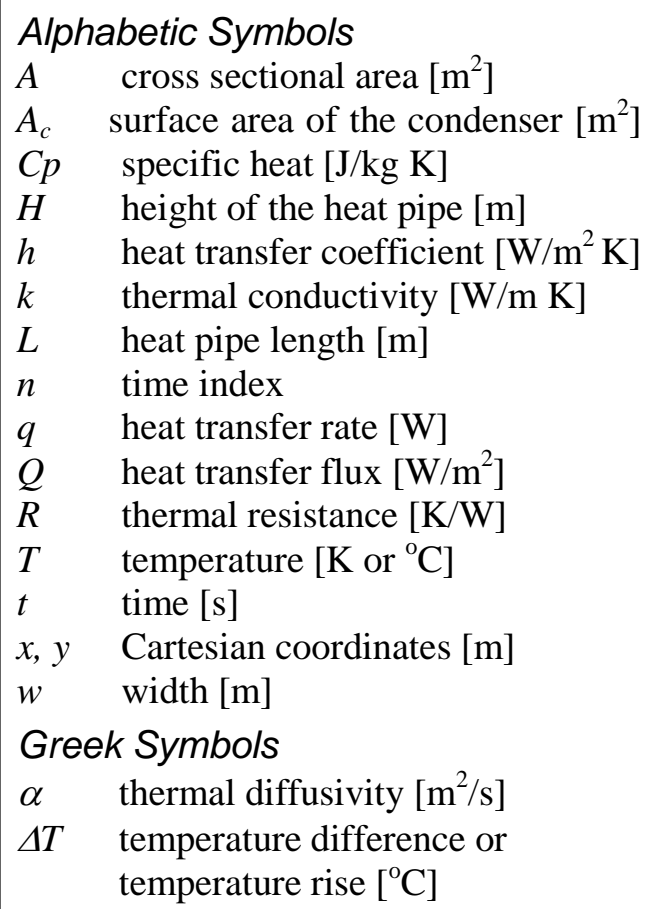

$\lambda \quad$ material thickness of the heat conductor $[\mathrm{m}]$

$\zeta, \eta \quad$ coefficient in differential equations

$\rho \quad$ density $\left[\mathrm{kg} / \mathrm{m}^{3}\right]$

$\varphi \quad$ wick porosity

\section{Subscripts}

$\infty \quad$ ambient

$i$ initial, conductor number

$i, 1$ or $\mathrm{i}, 2$ end of heat conductor

$c$ condenser

$e$ evaporator

eff effective

$l \quad$ liquid

$o$ outer surface

$s \quad$ solid

wa wall

wi wick

Wang and Vafai [10] investigated experimentally the thermal steady state performance of a heat pipe. The heat pipe was $190.50 \mathrm{~mm}$ in length, $139.70 \mathrm{~mm}$ in width and 34.93 in height. The heat pipe walls were made of copper plate, $3.175 \mathrm{~mm}$ thick. The vapor region was composed of 4 identical channels. The wicks were composed of sintered copper powder with a thickness of $1.651 \mathrm{~mm}$. The input heat flux was in the range of $425-1780 \mathrm{~W} / \mathrm{m}^{2}$. The average total heat transfer coefficient was $12.4 \mathrm{~W} / \mathrm{m}^{2}{ }^{\circ} \mathrm{C}$. Comparison between the steady state experimental results with the analytical model developed in their study show good agreement. It was found that the porous wick in the evaporator section had the main thermal resistance.

Wang and Vafai [11] studied the transient behavior of the previously described heat pipe during startup and shutdown. The input heat flux was in the range of 5580$15500 \mathrm{~W} / \mathrm{m}^{2}$. The heat transfer coefficient range was 285 to $1260 \mathrm{~W} / \mathrm{m}^{2}{ }^{\circ} \mathrm{C}$ with an uncertainty of $\pm 5.8 \%$ to $13.9 \%$. Comparisons between the analytical model and the experimental results during startup and shutdown show good agreement between them [11]. It was found that the porous wick in the evaporator section had the main thermal resistance and the maximum temperature rise increases linearly with the input heat flux. The maximum temperature difference within the heat pipe mainly depends on the input power. The time to reach the steady state condition was found to be affected strongly by the heat transfer coefficient. The wicks in the evaporator and condenser sections have significant magnitudes in the total thermal resistance. An empirical correlation to calculate the maximum temperature rise was given for the specific heat pipe they investigated. Also, the same authors [11] developed an analytical model to 
predict the transient performance of a flat plate heat pipe for both the startup and shutdown operations. One of the main assumptions was that the temperature in the vapor phase is uniform.

The network model is an attractive way to study the behavior of heat pipes. In some practical situations, many details are not required to design heat pipes. So, there is no need to solve the governing equations (Navier-Stokes and energy equations) and the deduced nonlinear partial differential equations using the finite difference or the finite element methods. Beside its simplicity, the computational time of the network model is so much less than that is needed for the solution of the previously mentioned governing equations. Thus, easy parametric study can be done with less computation time.

Faghri [1] analyzed the steady state operation of conventional heat pipes using the network model. The heat pipe was divided into ten components each of which had a specific thermal resistance. Zuo and Faghri [12] used the network analysis to study the transient behavior of conventional heat pipe. The governing equations were reduced to six first-order, linear, ordinary differential equations which were solved using Runge-Kutta method. Comparison with previous experimental and numerical results validated the network model.

In the present study, a simple model is developed based on the network analysis for a flat plate heat pipe. Comparisons of the results obtained using this network model with some of the existing experimental data during the startup and shutdown are done. A parametric study is conducted to study the influence of some factors on the evaporator and condenser transient temperatures. Finally a general expression to estimate the maximum temperature difference is derived and compared with some experimental data.

\section{THEORETICAL ANALYSIS}

\subsection{Physical Model}

Figure 1 shows a schematic of a two-dimensional symmetric flat plate heat pipe used in the present study. The evaporator is located along the centerline of the top surface of the heat pipe. The condenser can be divided into five sections; two smaller identical condenser sections on the top, located on either sides of the evaporator section, two smaller identical condenser sections on either side of the heat pipe, and a larger condenser section on the bottom.

The main assumptions considered in the present analysis are:

1. Two- dimensional flow.

2. Constant properties for the vapor and liquid.

3. Constant ambient temperature around the heat pipe.

4. The heat transfer in the wick is by conduction.

5. The heat transfer by radiation is neglected. 


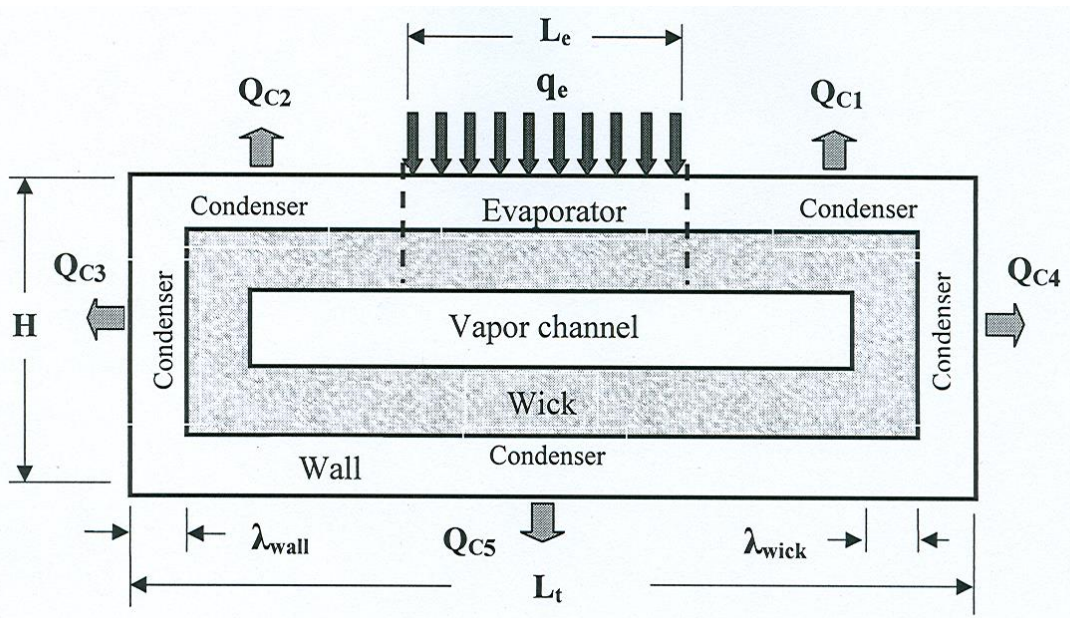

Fig. 1: Schematic of a two dimensional symmetric flat plate heat pipe

\section{$2.2 \quad$ Network model}

The flat plate heat pipe consists of a number of components with different thermal resistances. A simple network model of the flat plate heat pipe, consisting of thermal resistances and a working fluid, is developed to analyze the flat plate heat pipe transient behavior. A similar network has been presented by Zuo and Faghri [12] for steady state conventional heat pipe analysis. Figure 2-a shows the flow of heat in a symmetric flat plate heat pipe describing the heat input branching. The flat plate heat pipe operation consists of twelve processes which can be classified into heat conduction and heat convection processes. The following are the descriptions of these branched heat processes:

1. The evaporator wall conduction

2. The evaporator wick heat conduction.

3. The vapor flow heat convection.

4. The wall heat conduction in the $x$ direction

5. The wick heat conduction in the $x$ direction

6. The heat convection due to liquid flow (illustrated by dashed line)

7. The condenser wick-upper-surface heat conduction

8. The condenser wall-upper surface heat conduction

9. The condenser wick side surface heat conduction

10. The condenser wall side-surface heat conduction

11. The condenser wick-lower surface heat conduction

12. The condenser wall-lower surface heat conduction

Figure 2-b shows the thermal network resistances corresponding to each one of the above heat processes of the flat plate heat pipe as well as the convection heat transfer at the condenser outer surfaces. Once the thermal resistance of each process is calculated, the heat pipe temperature in any process can be obtained and other parameters can be easily calculated. To simplify the network shown in Fig. 2-b, the following can be considered. 
i. The vapor flow thermal resistance (3) is considerably small compared to the other resistances and can be neglected.

ii. The effect of the liquid return resistance (6) can be neglected, [12].

iii. The resistances 4 and 5 in the $x$ direction are high compared to the other resistances, and just small amount of heat can be transferred in the $\mathrm{x}$ direction, so the effect of these two resistances can be neglected too.

With the assumption of equal heat transfer coefficient and ambient temperature around the heat pipe, the network of the flat plate heat pipe can be reduced to a simple one, as shown in Fig. 3, with neglecting of the contact resistance between the heat source and the evaporator. In many practical situations, the effect of the radiation heat transfer is not significant compared to the convection heat transfer. So in this analysis, the cooling by convection is only included, [8]. Based on the assumption in this study, the network model can be simplified to four processes. The four network processes shown in Fig. 3 are as follows:

1. The evaporator wall heat conduction.

2. The evaporator wick heat conduction.

3. The condenser wick heat conduction.

4. The condenser wall heat conduction.

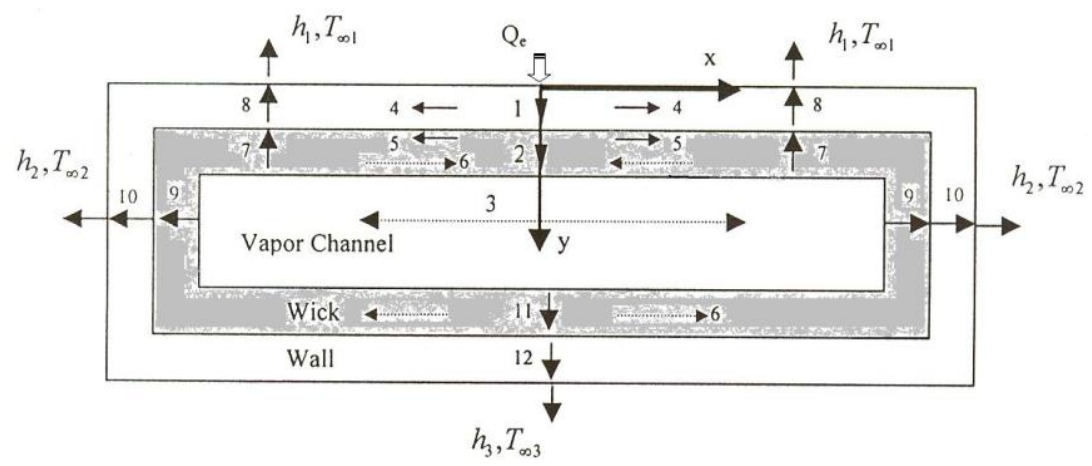

(a)

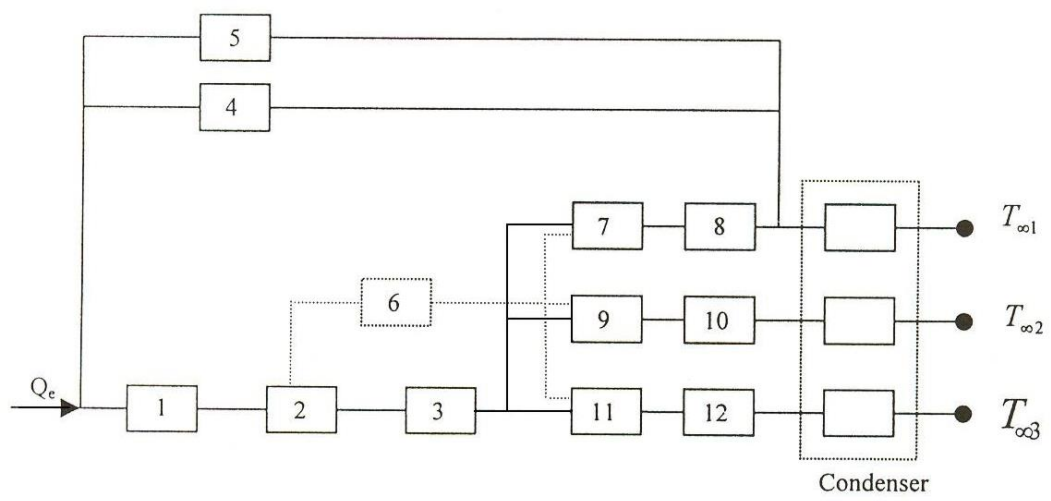

(b)

Fig. 2: Network system of a flat plate heat pipe operation. (a) Schematic of the heat flow in a flat plate heat pipe; (b) A network analogy of the flat plate heat pipe heat transfer 
The above argument implies that transient temperature behavior of the flat plate heat pipe mainly depends of the wall and wick heat conduction. Since, the heat pipe is simply represented by four-one dimensional heat conduction components. Figure $3 \mathrm{~b}$ shows one of the components with cross sectional area $A_{i}$ and a thickness of $\lambda_{i}$. Assuming the temperature of the middle of the component is $T_{i}$ and the temperatures of its two ends are $T_{i, 1}$ and $T_{i, 2}$. Since, $\lambda_{i}$ is small, the linear approximation of the Fourier's law can be used. The energy balance equations can be obtained as follows.

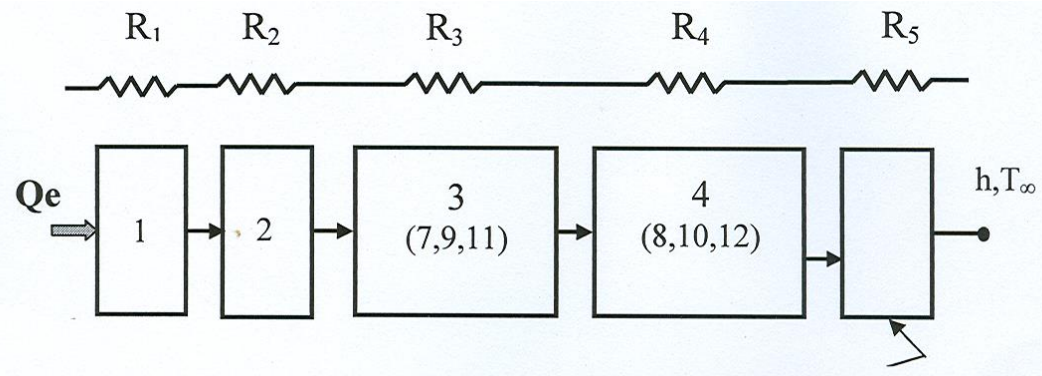

Resistance due to convection

(a)

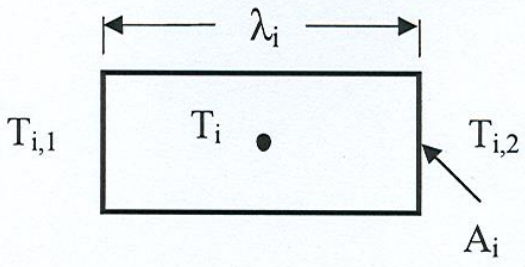

(b)

Fig.3. System of a flat plate heat pipe operation. (a) Thermal resistance network of the flat plate heat pipe; (b) One dimensional heat conductor

$$
\begin{aligned}
& \rho_{i} A_{i} \lambda_{i} C p_{i} \frac{d T_{i}}{d t}=Q_{i, 1}-Q_{i, 2} \\
& Q_{i, 1}=\frac{T_{i, 1}-T_{i}}{R_{i} / 2}, \quad \mathrm{Q}_{\mathrm{i}, 2}=\frac{T_{i}-T_{i, 2}}{R_{i} / 2} \quad \text { and } \quad R_{i}=\frac{\lambda_{i}}{k_{i} A_{i}}
\end{aligned}
$$

It should be noted that the input and output heat fluxes have been linearly approximated using Fourier's Law. If $\lambda_{i}$ is very large, this linear assumption may cause some errors. The component should then be divided into a series of heat conductors to ensure a smaller $\lambda$ for each heat conductor. Rearranging the above equations, yields

$$
\frac{d T_{i}}{d t}=\frac{2 \alpha_{i}}{\lambda_{i}^{2}}\left(T_{i, 1}+T_{i, 2}-2 T_{i}\right)
$$

Equation (3) is the governing equation for each of the four components in the flat plate heat pipe network, as shown in Fig. 3. 
Based on fundamental heat transfer principles, the system must obey the following two rules: (1) at any vertex, the summation of input heat flows equals the summation of output heat flows; and (2) the components (heat conductors) with a common vertex experience the same temperature at the corresponding ends.

The above heat transfer principles, yields

$$
T_{i, j}=T_{j, i}, \mathrm{i} \text { and } \mathrm{j}=1,2,3,4 \mathrm{i} \neq \mathrm{j}
$$

and

$$
Q_{i, 2} \cong Q_{j, 1} \text { i and } \mathrm{j}=1,2,3,4 ; \mathrm{j}>\mathrm{i}
$$

From equations (2) - (5) the following four governing equations describing the heat pipe thermal transient behavior are deduced

$$
\begin{aligned}
\frac{d T_{1}}{d t} & =\frac{2 \alpha_{1}}{\lambda_{1}^{2}}\left[R_{1} Q_{e} / 2+\left(\zeta_{1,2}-1\right) T_{1}+\zeta_{2,1} T_{2}\right] \\
\frac{d T_{2}}{d t} & =\frac{2 \alpha_{2}}{\lambda_{2}^{2}}\left[\zeta_{1,2} T_{1}+\left(\zeta_{2,1}+\zeta_{2,2}-2\right) T_{2}+\zeta_{3,2} T_{3}\right] \\
\frac{d T_{3}}{d t} & =\frac{2 \alpha_{3}}{\lambda_{3}^{2}}\left[\zeta_{2,3} T_{2}+\left(\zeta_{3,2}+\zeta_{3,4}-2\right) T_{3}+\zeta_{4,3} T_{4}\right] \\
\frac{d T_{4}}{d t} & =\frac{2 \alpha_{4}}{\lambda_{4}^{2}}\left[\zeta_{3,4} T_{3}+\left(\zeta_{4,3}+\eta-2\right) T_{4}+\frac{h \mathrm{AcT}_{\infty} / 2}{k_{4} A_{4} / \lambda_{4}+h \mathrm{~A}_{\mathrm{c}} / 2}\right]
\end{aligned}
$$

Where

$$
\begin{gathered}
\zeta_{i, j}=\frac{1 / R_{i}}{1 / R_{i}+1 / R_{j}} \\
\eta=\frac{1 / R_{4}}{1 / R_{4}+h \mathrm{~A}_{\mathrm{c}} / 2}
\end{gathered}
$$

Equations (6-9) are first order, linear ordinary differential equations that can be solved to get the temperatures of the four components in the network model. The implicit finite difference scheme is used to convert the four ordinary differential equations to the following four algebraic equations.

$$
\begin{aligned}
& \frac{T_{1}^{n+1}-T_{1}^{n}}{\Delta t}=\frac{2 \alpha_{1}}{\lambda_{1}^{2}}\left[R_{1} Q_{e} / 2+\left(\zeta_{1,2}-1\right) T_{1}^{n+1}+\zeta_{2,1} T_{2}^{n+1}\right] \\
& \frac{T_{2}^{n+1}-T_{2}^{n}}{\Delta t}=\frac{2 \alpha_{2}}{\lambda_{2}^{2}}\left[\zeta_{1,2} T_{1}^{n+1}+\left(\zeta_{2,1}+\zeta_{2,2}-2\right) T_{2}^{n+1}+\zeta_{3,2} T_{3}^{n+1}\right] \\
& \frac{T_{3}^{n+1}-T_{3}^{n}}{\Delta t}=\frac{2 \alpha_{3}}{\lambda_{3}^{2}}\left[\zeta_{2,3} T_{2}^{n+1}+\left(\zeta_{3,2}+\zeta_{3,4}-2\right) T_{3}^{n+1}+\zeta_{4,3} T_{4}^{n+1}\right] \\
& \frac{T_{4}^{n+1}-T_{4}^{n}}{\Delta t}=\frac{2 \alpha_{4}}{\lambda_{4}^{2}}\left[\zeta_{3,4} T_{3}^{n+1}+\left(\zeta_{4,3}+\eta-2\right) T_{4}^{n+1}+\frac{h \mathrm{AcT}_{\infty} / 2}{k_{4} A_{4} / \lambda_{4}+h \mathrm{~A}_{\mathrm{c}} / 2}\right]
\end{aligned}
$$


The abovementioned four algebraic equations (equations 12-15) subject to the initial conditions are solved using the matrix inverse method. The initial conditions for the flat plate heat pipe are given as:

$$
\begin{aligned}
& T_{w a}=T_{w a, i} \\
& T_{w i}=T_{w i, i}
\end{aligned}
$$

where $T_{w a, i}$, and $T_{w i, i}$, are the initial temperature of the wall and wick respectively.

\subsection{Heat Transfer Coefficient}

The heat transfer coefficient under steady state conditions on the surfaces of the condenser section can be calculated from the following equation:

$$
h=\frac{Q / A_{c}}{T_{w a, o c}-T_{\infty}},
$$

where $Q, A_{c}, T_{\infty}$ and $T_{w a, o c}$ are the input power, total area of the condenser section, ambient temperature and condenser outer surface temperature, respectively.

Because heat pipes are two-phase heat transfer devices that do not have relatively constant thermal conductivities like solid materials, an effective thermal conductivity is used. The equation used to calculate the effective thermal conductivity for the wick of heat pipe is [11]:

$$
k_{w i}=k_{e f f}=k_{1}\left[\frac{k_{l}+k_{s}-(1-\varphi)\left(k_{l}-k_{s}\right)}{k_{l}+k_{s}+(1-\varphi)\left(k_{l}-k_{s}\right)}\right]
$$

The values of the effective properties used in this study along with other properties such as the wick thermal conductivity, wick density, and liquid density are shown in Table (1).

In addition to the maximum heat transport rate, the total thermal resistance is another important feature of a heat pipe. To evaluate the total thermal resistance, as depicted in Fig. 3, a simplified model for the thermal resistance of the flat plate heat pipe used in this study can be written as:

$$
Q_{e}=\frac{\Delta T}{R_{\text {total }}}
$$

where $R_{\text {total }}$ is the summation of the five resistances of the simple network model as shown in Fig. 3. Therefore, the total thermal resistance can be determined as follows:

$$
R_{\text {total }}=\frac{\lambda_{1}}{k_{1} A_{1}}+\frac{\lambda_{2}}{k_{2} A_{2}}+\frac{\lambda_{3}}{k_{3} A_{3}}+\frac{\lambda_{4}}{k_{4} A_{4}}+\frac{1}{h A_{c}}
$$

For the flat plate heat pipe under investigation

$$
\begin{aligned}
& A_{1}=A_{2}, \quad \mathrm{~A}_{3}=A_{4}=A_{c} \\
& k_{1}=k_{4}=k_{w a}, \quad \mathrm{k}_{2}=k_{3}=k_{\text {eff }} \\
& \lambda_{1}=\lambda_{4}=\lambda_{w a}, \quad \lambda_{2}=\lambda_{3}=\lambda_{w i}
\end{aligned}
$$




\section{RESULTS AND DISCUSSION}

This section addresses the validity of the present thermal network model in a flat plate heat pipe by comparing its results with other experimental results. The geometrical conditions and properties for the calculated results of the network model presented in this study are the same as those used in the experiments done by Wang and Vafai [10, 11]. The heat pipe specifications are, $190.50 \mathrm{~mm}$ in length, $139.7 \mathrm{~mm}$ in width, and $34.93 \mathrm{~mm}$ in height. The heat pipe walls are made of copper plate with $3.175 \mathrm{~mm}$ in thickness. Porous wicks are used which are composed of sintered copper powder with a thickness of $1.651 \mathrm{~mm}$. The pore radius of the wicks was $3.1 \times 10^{-5} \mathrm{~m}$ and their porosity is 50 percent. The working fluid is water. A heater, $139.7 \mathrm{~mm}$ in length and $50.8 \mathrm{~mm}$ in width, is attached along the centerline of the top surface of the heat pipe. The four side surfaces of the heat pipe are insulated. For the set of experiments done by Wang and Vafai [10], the average heat transfer coefficient was experimentally estimated to be $12.4 \mathrm{~W} / \mathrm{m}^{2}{ }^{\circ} \mathrm{C}$ with a maximum predicted error of $\pm 7 \%$. In the Wang and Vafai experimental work $[10,11]$, the heat pipe was positioned horizontally while cooling water is used to dissipate the heat from the heat pipe condenser. The heat transfer coefficients ranged from $285 \mathrm{~W} / \mathrm{m}^{2}{ }^{\circ} \mathrm{C}$ with $\pm 5.8 \%$ uncertainty to $1260 \mathrm{~W} / \mathrm{m}^{2}{ }^{\circ} \mathrm{C}$ with \pm $13.9 \%$ uncertainty. The maximum uncertainty in the power supply readings is $\pm 3.4 \%$. Temperatures were measured on the outer surface of the evaporator and the condenser sections.

Table (1) contains the properties of the wall material and effective properties of the wick used in the model for this study. All the properties are evaluated at temperature of $300 \mathrm{~K}$. The properties of the solid material in the wick are the same as of the material of the wall.

Table 1. Values of properties used in the flat-plate heat pipe simulations.

\begin{tabular}{|c|c|c|c|c|c|c|c|c|}
\hline$k_{w a}$ & $\begin{array}{c}k_{l} \\
\left(\mathrm{~W} / \mathrm{m}^{\circ} \mathrm{C}\right)\end{array}$ & $k_{w i}$ & $C p_{w a}$ & $\begin{array}{c}C p_{l} \\
\left(\mathrm{~J} / \mathrm{kg}^{\circ} \mathrm{C}\right)\end{array}$ & $C p_{\text {eff }}$ & $\rho_{w a}$ & $\begin{array}{c}\rho_{l} \\
\left(\mathrm{~kg} / \mathrm{m}^{3}\right)\end{array}$ & $\rho_{\text {eff }}$ \\
\hline 401 & 0.6118 & 1.8821 & 386 & 4181 & 2282.5 & 8930 & 996.9 & 4972 \\
\hline
\end{tabular}

Figures 4 and 5 show the comparison of the network model results with the experimental results obtained by Wang and Vafai $[10,11]$. These figures show the temporal temperature distribution on the outside wall surface of the flat plate heat pipe for different sets of input heat fluxes, $q_{e}$. Figure 4 shows the comparison for low heat transfer coefficients $\left(h=11.6\right.$ to $\left.12.9 \mathrm{~W} / \mathrm{m}^{2}{ }^{\circ} \mathrm{C}\right)$ and low input heat fluxes $\left(q_{e}=557\right.$, 796,1370 , and $1690 \mathrm{~W} / \mathrm{m}^{2}$ ). The time step is chosen to be 10 seconds. The network model correctly predicted the general trends of the flat plate heat pipe transients and good agreement is achieved. At steady state the difference between the network and the experimental results is less than $1{ }^{\circ} \mathrm{C}$. There is some difference after starting up for the evaporator and condenser sections. Figure 5 shows the comparison between the network model and the experimental results obtained by Wang and Vafai [11] for high heat transfer coefficient $\left(h=1050\right.$ to $\left.1090 \mathrm{~W} / \mathrm{m}^{2}{ }^{\circ} \mathrm{C}\right)$ and high input heat fluxes $\left(q_{e}=\right.$ $7060,8530,9920$ and $11200 \mathrm{~W} / \mathrm{m}^{2}$ ). For the network model, the time step used is 1 seconds. As can be seen in Figs. 4 and 5, the maximum top wall surface temperature 
increases with an increase in input heat flux, and the network model results were found to be in good agreement with the experimental results.
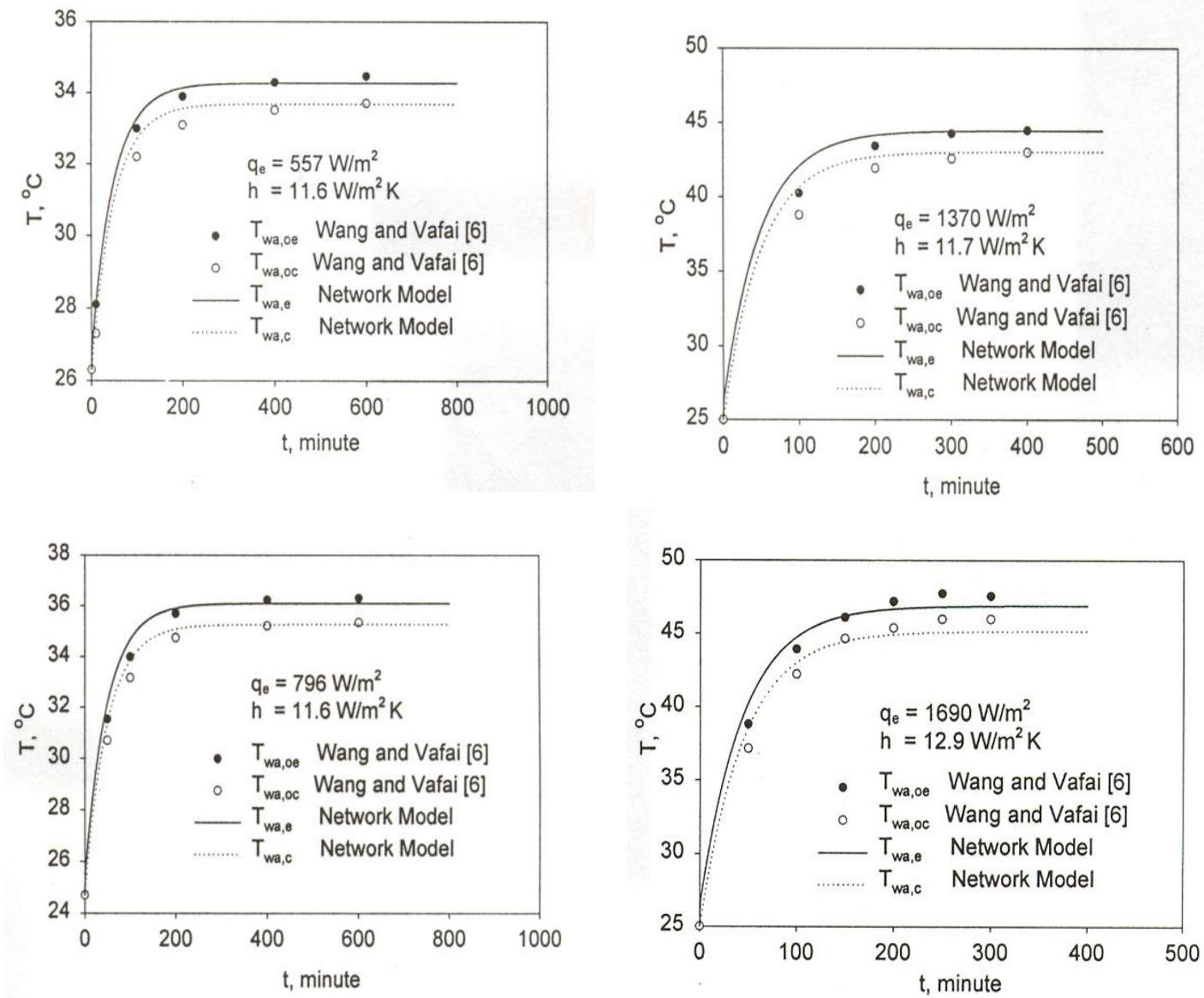

Fig. 4. Comparison of the network model transient response of a flat plate heat pipe with available experimental data obtained for different input heat fluxes, Wang and Vafai, [10].

Figure 6 shows comparisons between the network model and the experimental results obtained by Wang and Vafai [11] for the temporal temperature distributions on the outside surfaces of the flat plate heat pipe for a cyclical operation. The results show that the network model successfully predicts the transient temperature distribution in case of cyclic operation. The run time for the network model is less than 1 seconds using PC computer.

From the previous comparisons, it is obvious that the present network model predicts excellently the transient temperature of the flat plate hat pipe in small computational time. Thus, the network model is used to study the effects of the important parameters on the thermal performance of the flat plate heat pipe. 

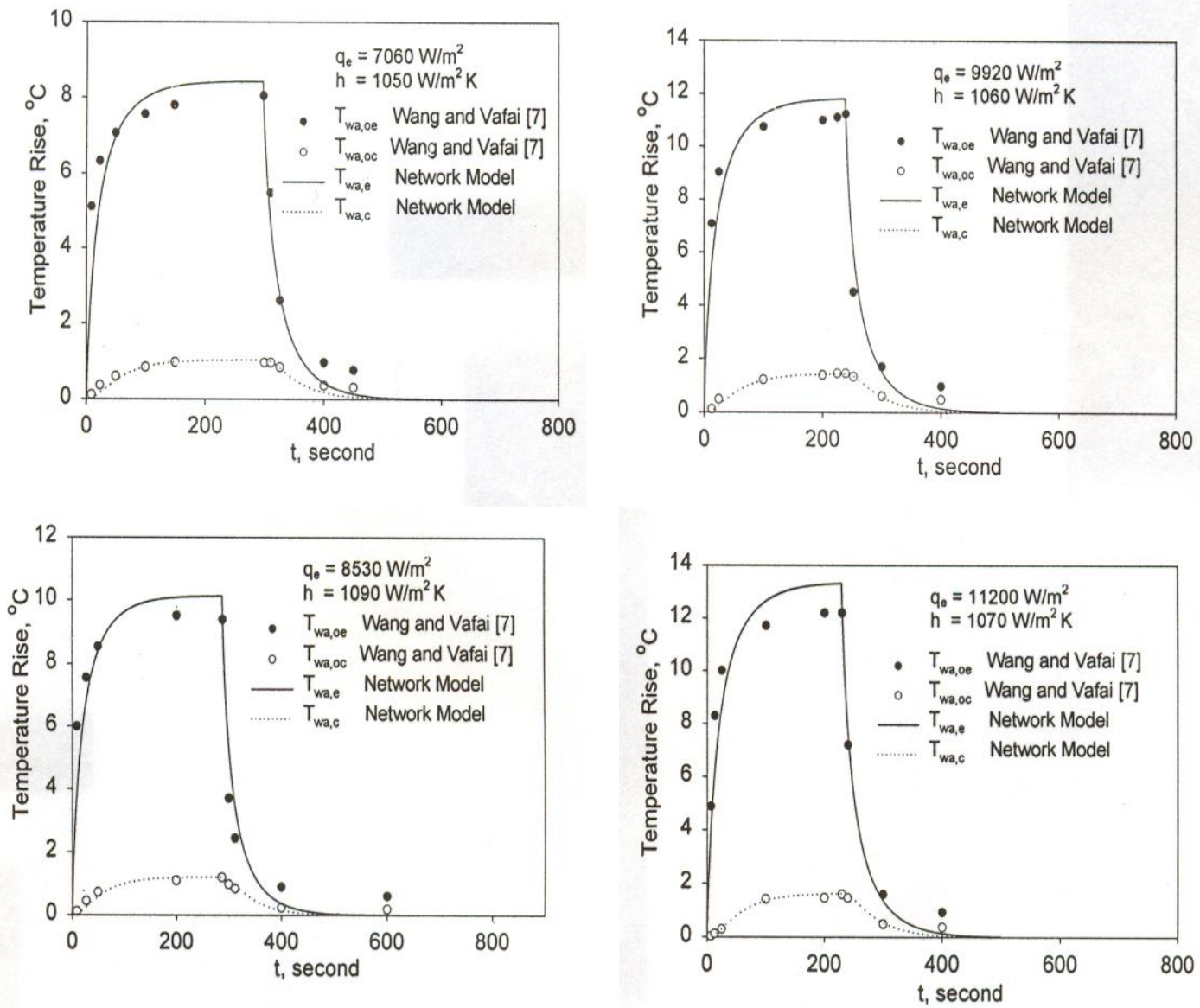

Fig. 5. Comparison of the network model transient response of a flat plate heat pipe with available experimental data obtained for different input heat fluxes, Wang and Vafai, [11].

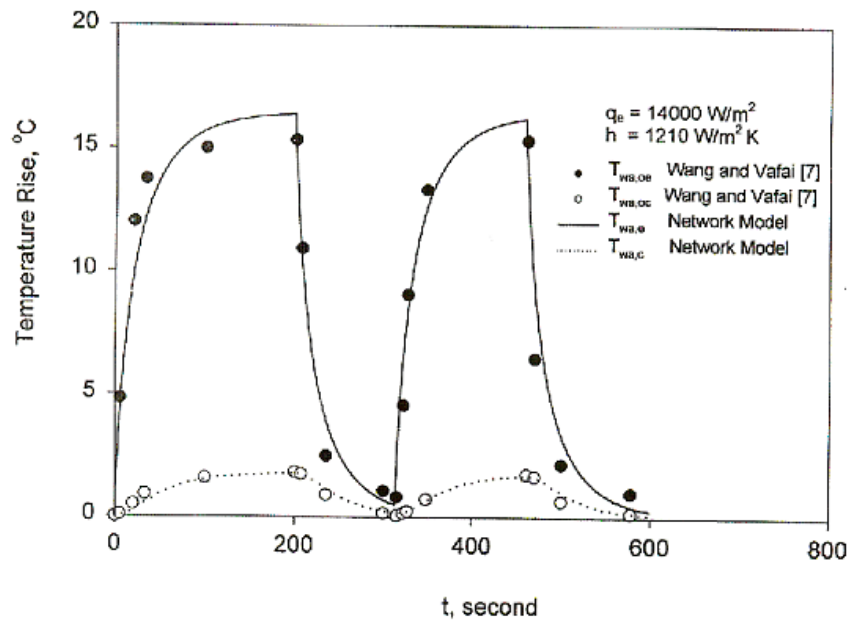

Fig. 6. Comparison of the transient temperature response of a flat plate heat pipe for a cyclic operation using network model and some of experimental data obtained by Wang and Vafai, [11] 


\section{Parametric Study}

In order to investigate the parameters that influence the performance of the flat plate heat pipe, studies for the effects of these parameters on the transient maximum and minimum temperature differences are conducted. Figure 7 presents the variation of temperature rise of the evaporator and the condenser with time for the flat plate heat pipe considered at different heat inputs values. Three different input heat fluxes values of 5000,10000 and $15000 \mathrm{~W} / \mathrm{m}^{2}$ are used, while the heat transfer coefficient was taken as $1000 \mathrm{~W} / \mathrm{m}^{2}{ }^{\circ} \mathrm{C}$ in the three cases. It is obvious that the steady-state temperature is higher for a heat pipe with the higher value of input heat flux. As expected, the value of the temperature rise in the evaporator and condenser sections increase with an increase in input heat flux. As can be seen, the maximum temperature rise changes linearly with the input heat fluxes.

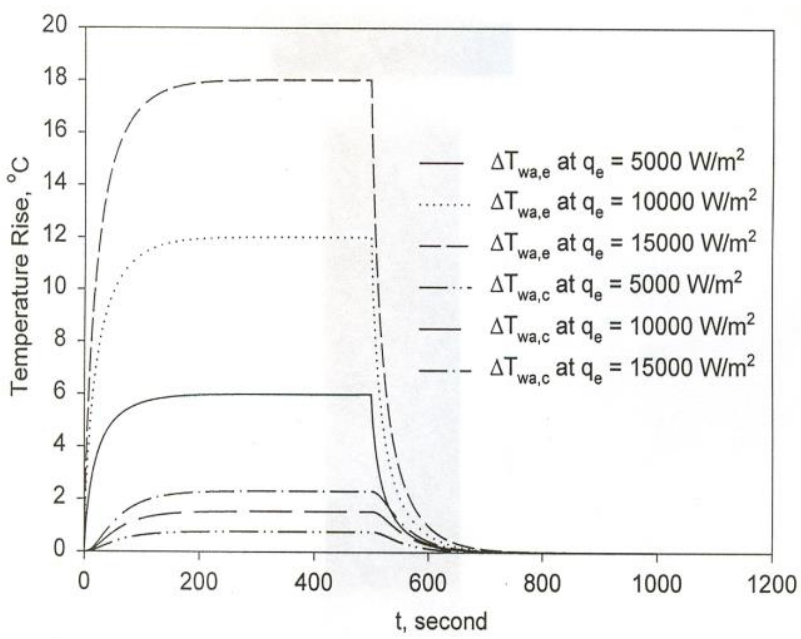

Fig. 7. Effect of input heat flux on the temperature rise of a flat plate heat pipe using network model at $h=1000 \mathrm{~W} / \mathrm{m}^{2 \circ} \mathrm{C}$.

Figure 8 shows the effect of heat transfer coefficient on the temperature rise of the evaporator and condenser. The values of the heat transfer coefficient are 500, 750 and $1000 \mathrm{~W} / \mathrm{m}^{2}{ }^{\circ} \mathrm{C}$, while the input heat flux was taken as $10000 \mathrm{~W} / \mathrm{m}^{2}$. As shown in Fig. 8, increasing the heat transfer coefficient reduces the surface temperatures on both the evaporator and condenser.

Figure 9 shows the effect of wall thermal conductivity on the temperature rise of evaporator and condenser. Three different wall thermal conductivity values of 100 , 250 , and $400 \mathrm{~W} / \mathrm{m}^{\circ} \mathrm{C}$ are used. The values of the heat transfer coefficient and the input heat flux were taken as $1000 \mathrm{~W} / \mathrm{m}^{2}{ }^{\circ} \mathrm{C}$ and $10000 \mathrm{~W} / \mathrm{m}^{2}{ }^{\circ} \mathrm{C}$, respectively. As can be seen in Fig. 9, changing the wall thermal conductivity has no appreciable effect on the transient temperature of the evaporator and condenser temperature rise. These little effects are attributed to the high thermal conductivities of the wall used in this study. 


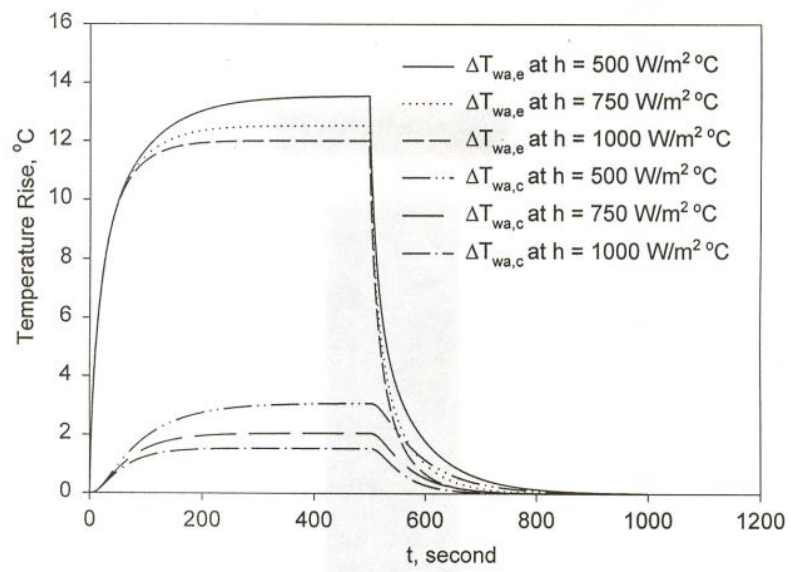

Fig. 8. Effect of heat transfer coefficient on the temperature rise of a flat plate heat pipe using network model at $q_{e}=10000 \mathrm{~W} / \mathrm{m}^{2}$.

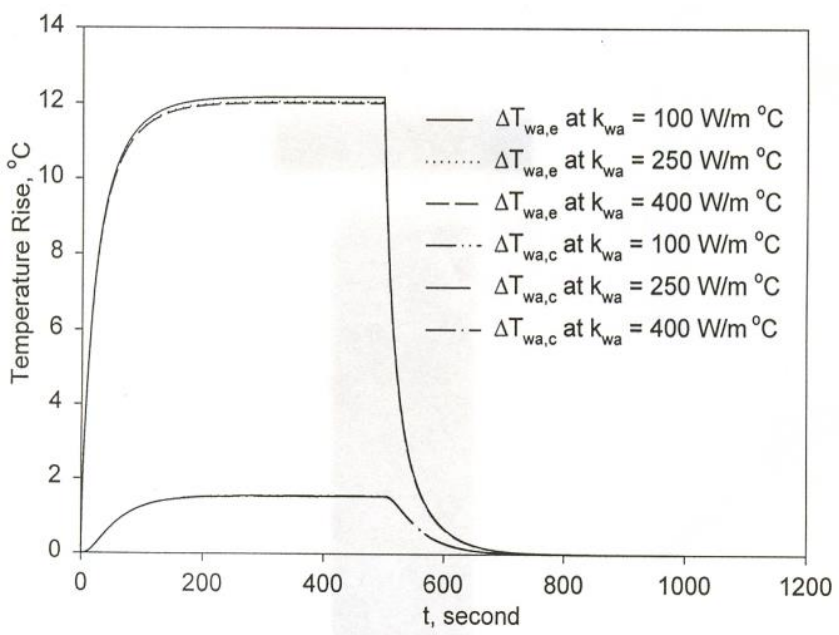

Fig. 9. Effect of wall thermal conductivity on the temperature rise of a flat plate heat pipe using network model at $h=1000 \mathrm{~W} / \mathrm{m}^{2 \circ} \mathrm{C}$ and $q_{e}=10000 \mathrm{~W} / \mathrm{m}^{2}$.

The effect of the wick effective thermal conductivity on the evaporator and condenser temperatures rise is shown in Fig. 10. For the porous wick of the heat pipe used by Wang and Vafai [10,11], the effective thermal conductivity of the wick is about $1.8821 \mathrm{~W} / \mathrm{m}{ }^{\circ} \mathrm{C}$, so accordingly the effective thermal conductivities used in this parametric study are 1,2 , and $3 \mathrm{~W} / \mathrm{m}{ }^{\circ} \mathrm{C}$. The values of the heat transfer coefficient and the input heat flux were taken as $1000 \mathrm{~W} / \mathrm{m}^{2}{ }^{\circ} \mathrm{C}$ and $10000 \mathrm{~W} / \mathrm{m}^{2}$, respectively. As can be seen in Fig. 10 the lower value of the effective thermal conductivity takes longer time to reach steady state. Moreover, the figure shows that changing the wick effective thermal conductivity has significant effects on the evaporator temperature rise, while it is difficult to observe its effects on the condenser temperature rise. 


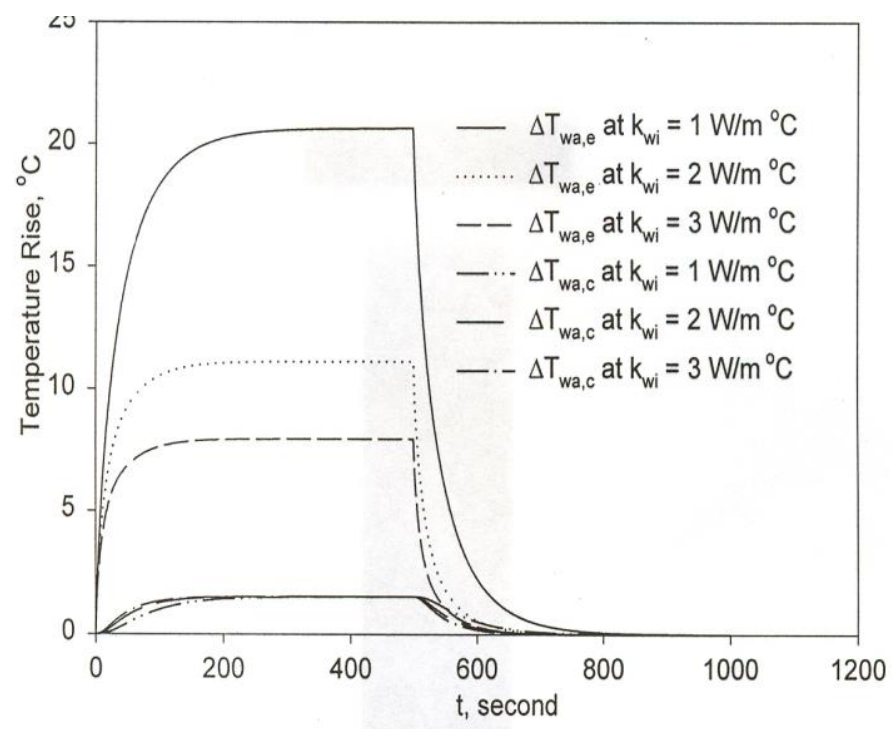

Fig. 10. Effect of wick thermal conductivity on the temperature rise of a flat plate heat pipe using network model at $h=1000 \mathrm{~W} / \mathrm{m}^{2 \circ} \mathrm{C}$ and $q_{e}=10000 \mathrm{~W} / \mathrm{m}^{2}$.

The wall thickness has nearly no effect on the steady state temperature rises as shown in Fig. 11. The values for the wall thickness were taken as 1,2 and $3 \mathrm{~mm}$. The figure shows that the higher value of wall thickness, takes longer time required to reach steady state. In case of changing the wick thickness, the evaporator temperature rise changes linearly with the wick thickness, as shown in Fig. 12. The wick thickness has no effect on the steady state condenser temperature rise.

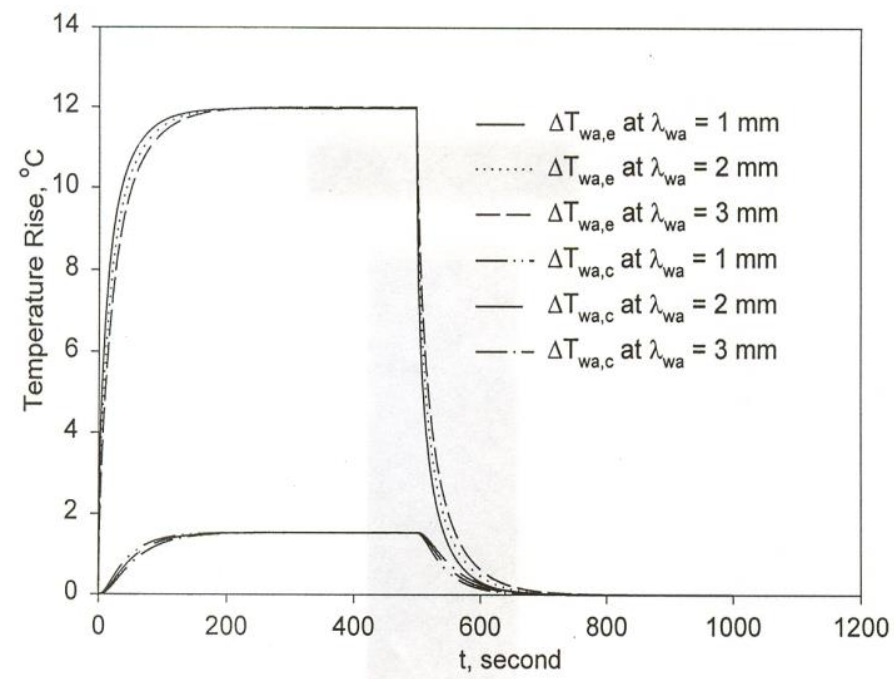

Fig. 11. Effect of wall thickness on the temperature rise of a flat plate heat pipe using network model at $h=1000 \mathrm{~W} / \mathrm{m}^{2 \circ} \mathrm{C}$ and $q_{e}=10000 \mathrm{~W} / \mathrm{m}^{2}$. 


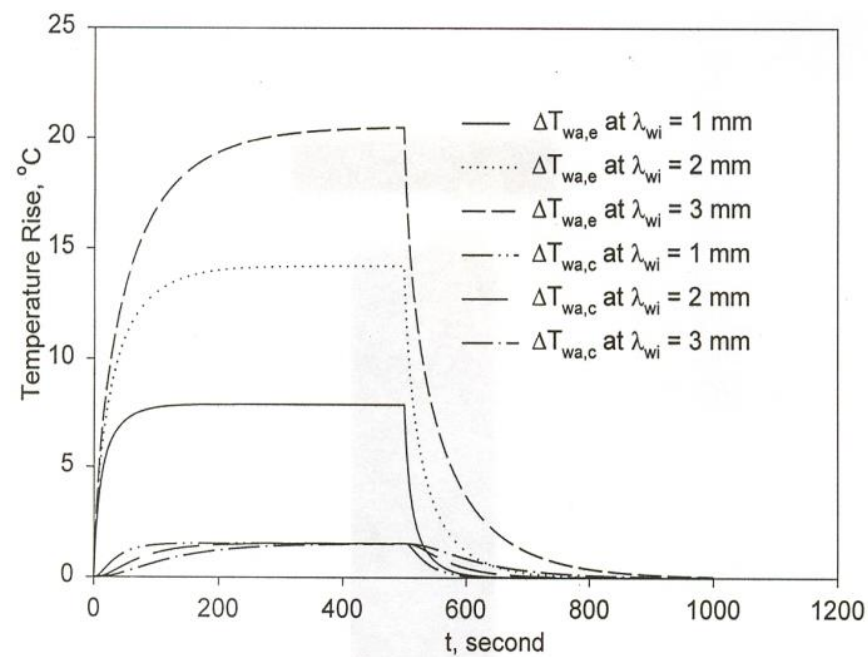

Fig. 12. Effect of wick thickness on the temperature rise of a flat plate heat pipe using network model at $h=1000 \mathrm{~W} / \mathrm{m}^{2 \circ} \mathrm{C}$ and $q_{e}=10000 \mathrm{~W} / \mathrm{m}^{2}$.

An important parametric study is the effect of the condenser surface area value on the temperature rise. Figure 13 shows the effect of three different values of the condenser surface area, 0.0461, 0.0923, and $0.1384 \mathrm{~m}^{2}$. As can be seen in Fig. 13, for a fixed input power and heat transfer coefficient, decreasing the condenser surface area reduces the time it takes to reach steady state conditions. However, the steady state temperature raises change with $1 / \mathrm{A}_{\mathrm{c}}$. The last parametric study is the effect of the wick porosity. Figure 14 shows the effect of three different values of the wick porosity, 0.4, 0.5, and 0.6. As can be seen in Fig. 14, for a fixed input power and heat transfer coefficient, increasing the wick porosity increases the value of evaporator temperature rise, while the porosity has no effect on the condenser steady state temperature rise. Also, the higher value of the wick porosity takes longer time than the lower value it takes to reach steady state.

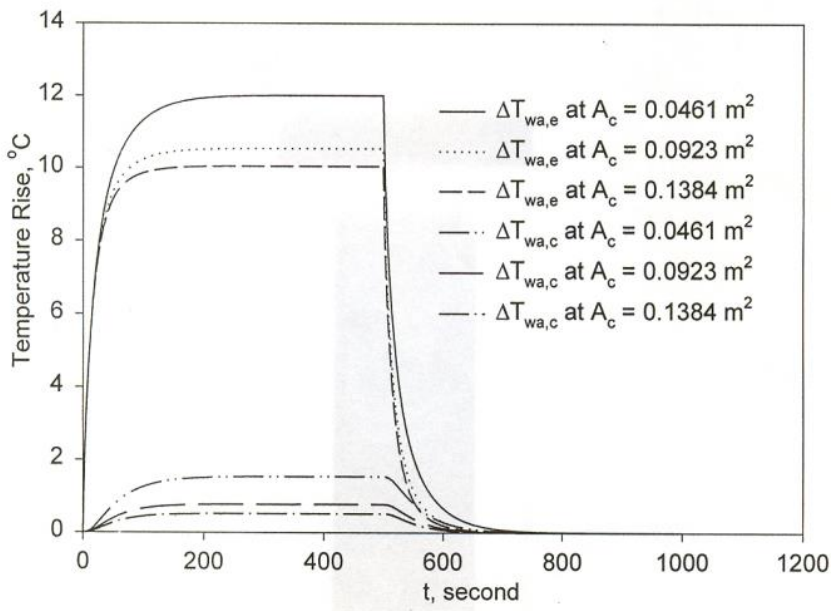

Fig. 13. Effect of condenser surface area on the temperature rise of a flat plate heat pipe using network model at $h=1000 \mathrm{~W} / \mathrm{m}^{2 \circ} \mathrm{C}$ and $q_{e}=10000 \mathrm{~W} / \mathrm{m}^{2}$. 


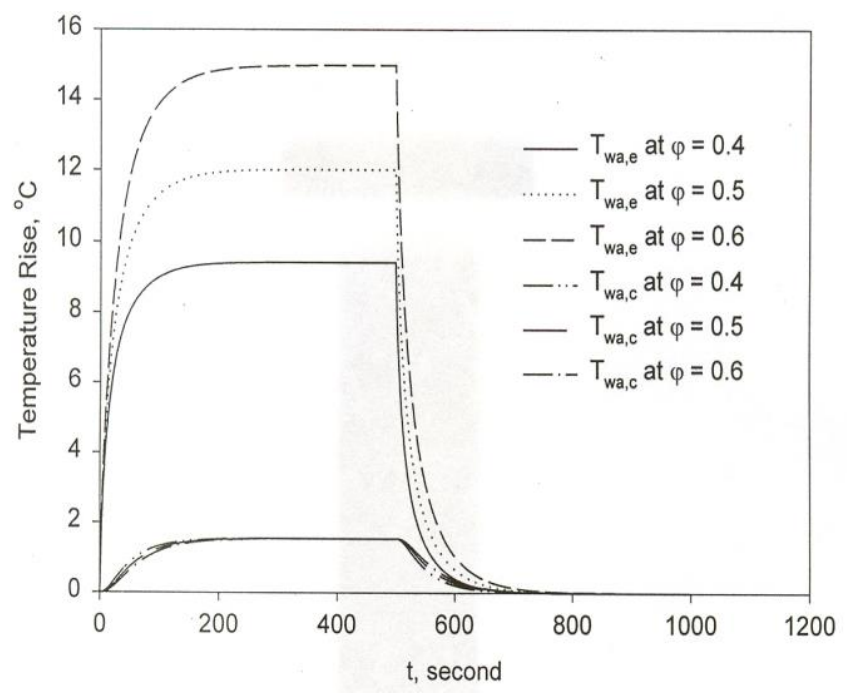

Fig. 14. Effect of porosity on the temperature rise of a flat plate heat pipe using network model at $h=1000 \mathrm{~W} / \mathrm{m}^{2 \circ} \mathrm{C}$ and $q_{e}=10000 \mathrm{~W} / \mathrm{m}^{2}$.

\section{CONCLUSIONS}

In this study the network modeling of flat plate heat pipe is presented. The heat pipe governing equations are reduced to four linear, first order, ordinary differential equations. Comparisons with the available experimental results show that the network model proved to give good prediction of the transient temperature profiles of the flat plate heat pipe.

Parametric study was conducted to study the effects of various parameters on the transient maximum and minimum temperature differences. It was found that the wick parameters (thermal conductivity, thickness and porosity) have significant effects on the maximum temperature difference. Also, the time for a specified flat plate heat pipe to reach steady state depends mainly on the heat transfer coefficient at the condenser side.

\section{REFERENCES}

1. Faghri, A., Heat Pipe Science and Technology, Taylor and Francis, Washington, DC, 1995.

2. G.P.Peterson, An Introduction to Heat Pipe: Modeling, Testing and Applications, Johan Wiley and Sons, New York, 1994.

3. Chi S., Heat Pipe Theory and Practices: A Sourcebook, Hemisphere Publishing Crop., Ney York, 1976.

4. Xiao, B., and Faghri, A., A Three-Dimensional Thermal-Fluid Analysis of Flat Heat Pipes, International Journal of Heat and Mass Transfer 51 (2008) 3113-3126.

5. Doa, K. H., Kim, S. J., and Garimella, S. V., A Mathematical Model for Analyzing the Thermal Characteristics of a Flat Micro Heat Pipe with a Grooved Wick, International Journal of Heat and Mass Transfer 51 (2008) 4637-4650. 
6. Lefevre, F., Rulliere, R., Pandraud, G., and Lallemand, M., Prediction of the Temperature Field in Flat Plate Heat Pipes with Micro-Grooves - Experimental Validation, International Journal of Heat and Mass Transfer 51 (2008) 4083-4094.

7. Sonan, R., Harmand, S., Pellé, J., Leger, D., and Fakès, M., Transient Thermal and Hydrodynamic Model of Flat Heat Pipe for the Cooling of Electronics Components, International Journal of Heat and Mass Transfer 51 (2008) 60066017.

8. Zhu, N., and Vafai, K., Vapor and Liquid Flow in an Asymmetrical Flat Plate Heat Pipe: A three Dimensional Analytical and Numerical Investigation, International Journal of Heat and Mass Transfer 41, (1998) 159-174.

9. Vafai, K., and Wang, Y., Analysis of Flow and Heat Transfer Characteristics of an Asymmetrical Flat Plate Heat Pipe, International Journal of Heat and Mass Transfer 35 (1992)2087-2099.

10. Wang, Y., and Vafai., K., An Experimental Investigation of the Thermal Performance of an Asymmetrical Flat Plate Heat Pipe, International Journal of Heat and Mass Transfer 43 (2000) 2657-2668.

11. Wang, Y., and Vafai, K., An Experimental Investigation of the Transient Characteristics on a Flat Plate Heat Pipe During Startup and Shutdown Operation, ASME Journal of Heat Transfer 122 (2000) 525-535.

12. Zuo, Z., J., and Faghri, A., A network Thermodynamic Analysis of the Heat Pipe, International Journal of Heat and Mass Transfer 41 (11) (1998) 1473-1484.

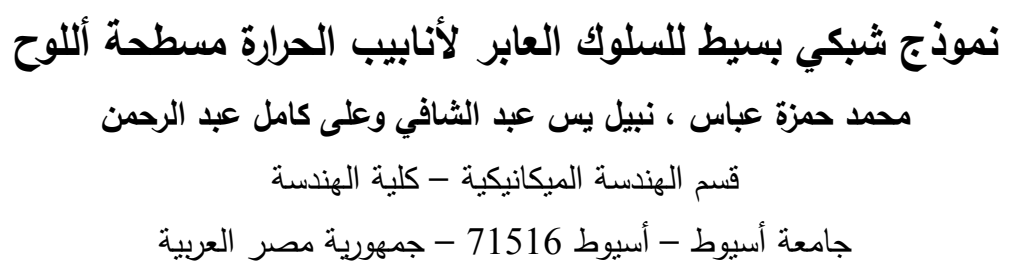

ملخص

في هذه الدراسة تم تطوير تحليل شبكي بسيط لدراسة الأداء الحراري العابر لأنابيب الحرارة مسطحة اللوح. تم توصيف السلوك العابر لأنابيب الحرارة مسطحة اللوح بالمعادلات التفاضلية العادية الخطية البسيطة من الدرجة الأولى والتي يمكن حلها بسهولة. تم إجراء مقارنة بين نتائج هذا النموذج المبسط مع بعض النتائج التجريبية المتاحة في البحوث المنشورة. لقد تبين ان هذا النموذج الثبكي يمكن أن يستخدم بنجاح لمحاكاة السلوك العابر لأنابيب الحرارة مسطحة اللوح. كما ثم إجراء دراسة بارامترية من اجل التعرف على تأثنر العوامل المختلفة على درجات الحرارة القصوى والدنيا لأنابيب الحرارة مسطحة اللوح. 